\title{
ANALISIS DAMPAK FASILITAS PEMBIAYAAN DENGAN PRODUK “QARDHUL HASAN UMKM” TERHADAPPENINGKATAN PENDAPATAN USAHA UMKM BINAANEL-ZAWA UIN MALIKI MALANG
}

\author{
Muhammad Nurul Hamdi \\ Latifah Safitri Handayani \\ EviNurjanah \\ Fakultas Ekonomi UIN Maulana Malik Ibrahim Malang \\ Jl. Gajayana No. 50 Malang
}

\begin{abstract}
Nowadays, stretching the entrepreneurial communitiy is quite dominate in Indonesia. Evident from his contributions in the history of the national economy are quite significant in 1998, Small Medium Enterprises can be seen as the saviour of the valve in the process of national economic recovery, both in pushing the pace of economic growth as well as the absorption of labour. Based on the data of the Ministry of cooperatives and SMEs in 2012, Small Medium Enterprises sector is the sector with the largest economy with a national economic prosentasi the involvement of the offender of $99.99 \%$. The sector absorbs the $97.15 \%$ of the labour force in Indonesia, and contributing to GDP on the basis of the applicable rates of $6.23 \%$.The purpose of this study is to examine, test, and evaluate the impact of financing facility with the products' qardhul hasan small medium enterprises' increased revenues against the small medium enterprises assisted el-Zawa Uin Maliki Malang. The population of this research are all Small Medium Enterprises that constitute the built el-Zawa at once using a financing facility with dana Qardh al-Hasan is 84. 30 of Small Medium Enterprises such as research samples. The results show that Qardhul Hasan SMEC products can increase the income of clients. In addition, the performance of the services provided by the customer is reasonably satisfied by the clients.
\end{abstract}

Keywords: Micro small and Medium Business, financing facility, Qardhul Hasan, el-Zawa UIN Maliki Malang.

Globalisasi yang identik dengan terbukanya pasar bebas internasional sudah sangat dekat. Tidak sampai setahun lagi, Masyarakat Ekonomi Asean akan resmi bergulir. Pasar bebas ini tidak hanya berdampak pada liberalisasi arus barang dan jasa, sumber daya manusia pun demikian. Sehingga penguatan segala aspek sebagai persiapan menghadapi hal ini menjadi mutlak dan cukup urgent untuk segera dilakukan atau masyarakat akan menjadi penonton saja dan tren "menjadi tuan di negeri sendiri.." hanya isapan jempol semata.

Dewasa ini, geliat wirausaha masyarakat semakin meningkat. Kegiatan ekonomi masyarakat yang tergolong pada Usaha Mikro Kecil dan Menengah (UMKM) ini pun cukup mendominasi di Indonesia. Terbukti dari kontribusinya dalam sejarah perekonomian nasional yang cukup signifikan. Terutama sejak krisis moneter tahun 1998, UMKM dapat dipandang sebagai katup penyelamat dalam proses pemulihan ekonomi nasional, baik dalam mendorong laju pertumbuhan ekonomi maupun penyerapan tenaga kerja. Trend pertumbuhan sektor ini juga kian menggembirakan (Wiyono, 2005).
Berdasarkan data Kementrian Koperasi dan UKM tahun 2012, sektor UMKM merupakan sektor dengan pelaku ekonomi terbesar dengan prosentasi keterlibatan pelaku ekonomi nasional sebesar 99,99\%. Sektor ini menyerap 97,15\% tenaga kerja di Indonesia, dan memberikan kontribusi terhadap PDB atas dasar harga berlaku sebesar 6,23\% (BPS, 2012). Berikut tabel perkembangan data UMKM dan usaha besar serta kontribusi terhadap Produk Domestik Bruto (PDB).

Dilihat dari data pada Tabel 1 kontribusi yang diberikan UMKM terhadap pertumbuhan perekonomian dan masyarakat Indonesia cukup signifikan. Tidak hanya itu, UMKM memiliki daya tahan terhadap resesi ekonomi global.Hal ini wajar, karena sektor ini tidak banyak terlibat dengan instrumen perekonomian global.UMKM juga memiliki beberapa keunggulan dibandingkan usaha besar diantaranya inovasi yang mudah terjadi dalam pengembangan produk, kemampuan menyerap tenaga kerja cukup banyak, fleksibilitas dan adaptasi terhadap perubahan pasar yang cepat (Zakiy dkk, 2014). 
Tabel 1 Perkembangan UMKM dan Usaha Besar Serta Kontribusi Terhadap PDB

\begin{tabular}{lccccc}
\hline \multicolumn{1}{c}{ Tahun 2012 } \\
\hline Satuan & Unit & \% & Tenaga Kerja & \% & Pertumbuhan PDB \\
\hline Usaha Mikro & $55,856,176$ & 98,79 & $99,859,517$ & 90,12 & $6,23 \%$ \\
Usaha Kecil & 629,418 & 1,11 & $4,535,970$ & 4,09 & \\
Usaha Menengah & 48,997 & 0.09 & $3,262,023$ & 2,94 & \\
Usaha Besar & 4,968 & 0,01 & $3,150,645$ & 2,84 & \\
\hline
\end{tabular}

Data diolah.Sumber: Kementrian Koperasi dan UKM, BPS

Fakta di atas sejatinya mendorong lembaga-lembaga keuangan di Indonesia untuk menyalurkan program pendanaannya pada sektor ini. Namun data yang dirilis Bank Indonesia tentang perkembangan baki debet kredit UMKM dan kredit perbankan menyatakan bahwa kredit UMKM per- April 2013 sebesar Rp. 555,626 Miliar lebih kecil dari pada non UMKM sebesar Rp. 2,287,112 Miliar. Berikut tabel perkembangan baki debet kredit UMKM dan kredit perbankan.

Tabel 2 Tabel Perkembangan Baki Debet Kredit UMKM

\begin{tabular}{lccc}
\hline Baki Debet & $\mathbf{2 0 1 1}$ & $\mathbf{2 0 1 2}$ & April-2013 \\
\hline Kredit UMKM & 479,887 & 552,226 & 555,626 \\
Kredit Non UMKM & $1,779,976$ & $2,226,731$ & $2,287,112$ \\
Kredit Perbankan & $2,259,862$ & $2,778,957$ & $2,842,738$
\end{tabular}

Sumber: bi.go.id

Hal ini mengindikasikan bahwa UMKM masih minim akan modal. Melihat kondisi perekonomian dunia yang semakin bebas, dan kontribusi UMKM terhadap perekonomian nasional yang signifikan maka perlu adanya upaya revitalisasi yang komprehensif usaha sektor ini.

Begitu juga dengan lembaga Zakat dan Wakaf "el-Zawa" UIN Maliki Malang. Produk "Qardhul Hasan UMKM", begitu nama programnya. Melihat pemaparan data di atas terkait minimnya penyaluran dana pada sektor UMKM menjadikan produk ini sangat dibutuhkan oleh para pengusaha sektor UMKM. Perlu diketahui bahwa sumber dana lembaga tersebut berasal dari zakat, infaq, shadaqah dan waqaf. Sehingga manajemennya tidak tertuntut untuk memperoleh feedback material atas kegiatan penyaluran dananya dan pemberdayaan stakeholder terkait menjadi lebih optimal.
Sungguhpun demikian, program ini perlu dievaluasi. Untuk melihat sejauh mana permodalan pada produk "Qardhul Hasan UMKM" ini berdampak pada peningkatan pendapatan UMKM tersebut. Karena permodalan yang tidak diiringi dengan pengetahuan mengelola keuangan dan kemampuan bisnis lainnya justru akan menimbulkan masalah baru. Terlebih tidak adanya tuntutan UMKM untuk menambahkan income-nya sebagai kewajiban tambahan atau biaya bunga yang timbul dari peminjaman modal pada umumnya. Sehingga menimbulkan pertanyaan bagaimana dampak fasilitas pembiayaan dengan produk 'qardhul hasan umkm' terhadap peningkatan pendapatan usaha umkm binaan el-Zawa Uin Maliki Malang?

\section{KAJIAN TEORI \\ Qardhul Hasan}

Qardh secara bahasa artinya adalah memotong. Sedangkan Hasan berarti baik. Qardh adalah sesuatu yang engkau berikan kepada seseorang yang suatu saat akan diminta kembali (Shalah, 2008). Qardhul Hasan adalah pemberian pinjaman tanpa imbalan tertentu atau keuntungan financial secara langsung. Qardhul Hasan disebut juga pembiayaan jasa karena pada prinsip dasarnya adalah akad ta'awun atau tabarru, yakni akad yang tujuannya tolong menolong dalam hal kebajikan bukan komersial.

Menurut Syafi' i Antonio (2001), Qardhul Hasan adalah pinjaman harta kepada mustahiq yang dapat diminta kembali tanpa imbalan lainnya selain pokok pinjaman. Jenis bantuan untuk pembiayaan usaha produktif dapat berupa modal bergulir untuk usaha mikro, sesuai target marketnya adalah fakir miskin yang mempunyai potensi pengembangan ekonomi. Berdasarkan keputusan fatwa yang dikeluarkan oleh Dewan Syariah Nasional, yang sesuai dengan fatwa DSNMUI Nomor 19/DSN-MUI/IV/2000 menyatakan bahwa Qardh adalah pinjaman. Sedang Al-Hasan 
adalah baik, maksudnya ketika seorang muslim meminjamkan atau menginfaqkan sesuatu yang ada pada dirinya hendaknya dia mengeluarkan sesuatu yang elok tanpa cela.

Di dalam al Qur'an surat Al-hadid ayat 11, pinjaman yang baik merupakan pengertian dari kata Qaradhan Hasanan, namun kata yang lebih banyak digunakan di kalangan para ahli adalah kata Qardhul Hasan yang artinya kegiatan penyaluran dana dalam bentuk pinjamam kebajikan tanpa imbalan dengan kewajiban pihak peminjam mengembalikan pokok pinjaman dalam waktu tertentu.

Dapat disimpulkan bahwa pembiayaan Qardhul Hasan merupakan suatu pembiayaan berupa pinjaman tanpa bunga dan tampa imbalan apapun kepada mustahiq. Mustahiq diwajibkan mengembalikan pinjaman pokoknya saja pada saat jatuh tempo yang sudah disepakati antar kedua belah pihak. Dasar landasan Qardhul Hasan sudah termuat dalam alQur'an, QS. Al-Hadid: 11, yang artinya: Siapakah yang mau meminjamkan kepada Allah pinjaman yang baik, maka Allah akan melipat-gandakan (balasan) pinjaman itu untuknya, dan dia akan memperoleh pahala yang banyak.

QS. Al-Baqarah: 245, yang artinya: Siapakah yang mau memberi pinjaman kepada Allah, pinjaman yang baik (menafkahkan hartanya di jalan Allah), maka Allah akan meperlipat gandakan pembayaran kepadanya dengan lipat ganda yang banyak. Dan Allah menyempitkan dan melapangkan (rezki) dan kepada-Nya-lah kamu dikembalikan.

\section{Pengertian UMKM}

Usaha Mikro adalah usaha produktif milik orang perorangan dan/atau badan usaha perorangan yang memenuhi kriteria Usaha Mikro sebagaimana diatur dalam Undang-Undang ini. Sedangkan Usaha Kecil adalah usaha ekonomi produktif yang berdiri sendiri, yang dilakukan oleh orang perorangan atau badan usaha yang bukan merupakan anak perusahaan atau bukan cabang perusahaan yang dimiliki, dikuasai, atau menjadi bagian baik langsung maupun tidak langsung dari usaha menengah atau usaha besar yang memenuhi kriteria Usaha Kecil sebagaimana dimaksud dalam Undang-Undang ini.

Usaha Menengah adalah usaha ekonomi produktif yang berdiri sendiri, yang dilakukan oleh orang perseorangan atau badan usaha yang bukan merupakan anak perusahaan atau cabang perusahaan yang dimiliki, dikuasai, atau menjadi bagian baik langsung maupun tidak langsung dengan Usaha Kecil atau usaha besar dengan jumlah kekayaan bersih atau hasil penjualan tahunan (Undang Undang Nomor 20 Tahun 2008).

\section{Pembiayaan}

Pembiayaan adalah pemberian fasilitas penyediaan dana untuk memenuhi kebutuhan pihak-pihak yang merupakan defisit unit. (M. Syafii Antonio, 2001:160). Pembiayaan dalam secara luas diartikan sebagai pendanaan yang dikeluarkan untuk mendukung investasi yang telah direncanakan baik dilakukan sendiri maupun dijalankan oleh orang lain. (Muhammad, $2002: 260$ )

Sesuai Keputusan Menteri Negara Koperasi dan Usaha Kecil dan Menengah nomor. 91/Kep/M.KUM/ IX/2004 dan menurut Undang-Undang Nomor 25 tahun 1992 tentang perkoperasian, peraturan pemerintah nomor 09 Tahun 1995 tentang kegiatan pelaksanaan usaha simpan pinjam oleh Koperasi Peraturan Menteri Negara Koperasi dan Usaha Kecil dan Menengah Republik Indonesia Nomor: 06/Per/ M.KUKMI/I/2007 tentang Petunjuk Teknis Program Pembiayaan produktif Koperasi dan Usaha mikro (P3KUM) Pola Syariah. Pembiayaan adalah kegiatan penyediaan dana untuk investasi atau kerjasama permodalan antara koperasi dengan anggota, calon anggota koperasi lain dan atau anggotannya yang mewajibkan penerima pembiayaan untuk melunasi pokok pembiayaan yang diterima kepada pihak koperasi sesuai akad disertai dengan pembayaran sejumlah bagi hasil dari pendapatan atau laba dari kegiatan yang dibiayai atau penggunaan dana pembiayaan tersebut.

Berdasarkan pengertian tersebut di atas, dapat ditarik kesimpulkan bahwa pembiayaan adalah pendanaan atau pemberian fasilitas penyediaan dana untuk mendukung investasi yang telah direncanakan berdasarkan kesepakatan antara pihak memilik dana dengan pihak lain yang mewajibkan pihak yang dibiayai untuk mengembalikan uang atau tagihan tersebut setelah jangka waktu tertentu dengan imbalan atau bagi hasil.

\section{Pemberdayaan}

Pengertian Pemberdayaan Masyarakat sebenarnya mengacu pada kata "Empowerment", yaitu sebagai upaya mengaktualisasikan potensi yang sudah dimiliki oleh masyarakat. Jadi pendekatan pemberdayaan masyarakat dalam pengembangan masyarakat adalah penekanan pada pentingnya masyarakat 
lokal yang mandiri sebagai suatu sistem yang mengorganisir diri mereka sendiri.Pendekatan pemberdayaan masyarakat yang demikian tentunya diharapkan memberikanperanan kepada individu bukan sebagai obyek, tetapi sebagai pelaku atau aktor yang menentukan hidup mereka sendiri. (Payne, 1997 : 266)

Konsep lain menyatakan bahwa pemberdayakan mempunyai dua makna, yakni mengembangkan, memandirikan, menswadayakan dan memperkuat posisi tawar menawar masyarakat lapisan bawah terhadap kekuatan-kekuatan penekan di segala bidang dan sektor kehidupan. Makna lainnya adalah melindungi, membela dan berpihak kepada yang lemah, untuk mencegah terjadinya persaingan yang tidak seimbang dan terjadinya eksploitasi terhadap yang lemah (Prijono dan Pranarka, 1996).

Dari uraian tersebut dapat disimpulkan bahwa pemberdayaan masyarakat merupakan suatu kegiatan atau tindakan untuk menswadayakan, mengembangkan kemandirian masyarakat khususnya kalangan menegah ke bawah terhadap kekuatandi segala bidang dan sektor kehidupan. Yang di dalamnya terdapat proses pengambilan keputusan sendiri untuk mengembangkan pilihan-pilihan adaptasi terhadap perubahan lingkungan dan sosial.

\section{Pengertian Pendapatan}

Pendapatan merupakan salah satu unsur yang paling utama dari pembentukan laporan laba rugi dalam suatu perusahaan. Banyak yang bingung dalam penggunaan istilah pendapatan. Hal ini disebabkan pendapatan dapat diartikan sebagai revenue dan dapat juga diartikan sebagai income.

Pengertian pendapatan dikemukakan oleh Dyckman (2002 :234) bahwa pendapatan adalah arus masuk atau peningkatan lainnya atas aktiva sebuah entitas atau penyelesaian kewajiban (atau kombinasi dari keduanya) selama satu periode dari pengiriman atau produksi barang, penyediaan jasa, atau aktivitas lain yang merupakan operasi utama atau sentral entitas yang sedang berlangsung.

Jadi dapat disimpulkan bahwa pendapatan merupakan penghasilan yang timbul dari suatu aktivitas perusahaan atau organisasi misalnya penjualan produk, barang dagang, atau jasa. Pengakuan pendapatan yaitu pada saat resiko berpindah kepada pembeli atau orang lain.

\section{METODE PENELITIAN}

Penelitian ini dilakukan di Lembaga Kajian Zakat dan Wakaf "El-Zawa" Universitas Islam Negeri Maulana Malik IbrahimMalang, Jl. Gajayana No. 50 Dinoyo, Malang. Peneliti memilih lokasi ini karena di dalamnya terdapat program permodalan berupa penyaluran dana, pendampingan, pemberdayaan serta pengkajian Usaha Mikro Kecil Menengah (UMKM). Unit ini sejatinya singkatan dari Zakat dan Wakaf. Lingkup kerja unit initerdiri dari berbagai wilayah Malang Raya seperti Gondanglegi, Tumpang, Dau, dan sekitar kampus UIN Maliki.

\section{Populasi dan Sampel}

Sampel penelitian adalah sebagian dari populasi yang diambil sebagai sumber data dan dapat mewakili seluruh populasi. Populasi dari penelitiaan ini adalah seluruh UMKM yang merupakan binaan el-Zawa sekaligus menggunakan fasilitas pembiayaan dengan dana Qardh al-Hasan UMKM adalah 84. Peneliti memilih 30 dari UMKM tersebut sebagai sampel penelitian.

\section{Definisi Operasional Variabel}

\section{Variabel Bebas (independent variable)}

Merupakan variabel yang diduga sebagai penyebab dari variabel lain, yaitu Qardhul Hasan adalah pemberian pinjaman tanpa imbalan tertentu atau keuntungan financial secara langsung. Qardhul Hasan disebut juga pembiayaan jasa karena pada prinsip dasarnya adalah akad ta'awun atau tabarru, yakni akad yang tujuannya tolong menolong dalam hal kebajikan bukan komersial.

\section{Variabel Terikat ( dependent variable)}

Merupakan variabel yang sebagai akibat atau dipengaruhi oleh variabel yang mendahuluinya. Dalam penelitian ini variabel terikatnya adalah pendapatan usaha.

\section{Metode dan Analisis Data}

Metode analisis yang digunakan dalam penelitian ini adalah metode analisis kuantitatif dengan menggunakan uji regresi linear berganda, dimana variabel terikatnya (Y) adalah pendapatan usaha dan variabel bebasnya (X) adalah produk Qardhul Hasan UMKM di el-Zawa 


\section{HASIL DAN PEMBAHASAN}

\section{Program unggulan El-Zawa}

\section{Beasiswa Mahasiswa Potensial}

Mencari ilmu adalah kewajiban bagi setiap Muslim dan Muslimat. Di era modern ini, kewajiban tersebut kadang terkendala oleh masalah finansial yang sering mengganggu kelancaran studi. Menyikapi hal itu, El-Zawa UIN Maliki memberikan bantuan beasiswa kepada mahasiswa yang kurang mampu dan memenuhi syarat yang telah ditentukan. Selain itu, El-Zawa memberikan training kewirausahaan bagi mahasiswa agar mereka mandiri dan mampu memenuhi kebutuhan studinya tanpa mengandalkan bantuan dari pihak lain.

\section{Beasiswa Yatim Unggul}

Nabi Muhammad SAW bersabda: "Saya dan Penjamin (Penolong) anak yatim seperti ini di surga (kemudian nabi member isyarat dengan jari telunjuk dan jari tengahnya" (HR. Bukhari-Muslim). Sehubungan dengan hadits tersebut, hingga 2012 El-Zawa memilki anak yatim binaan dari 6 RW sekitar kampus UIN Maliki.Mereka terdiri dari siswa TK, SD, dan SMP. Setiap anak yatim mendapat bantuan beasiswa pendidikan setiap bulannya antara Rp 75.000,- sampai Rp 125.000,-. Dana tersebut ditransfer langsung melalui rekening BTN tabungan Junior dan Tabungan Juara tanpa biaya administrasi bulanan.

\section{Qordhul Hasan Karyawan}

Qordhul Hasan adalah bentuk pinjaman tanpa bunga. Hal itu merupakan salah satu kepedulian ElZawa UIN Maliki Malang kepada para karyawan kontrak UIN Maliki Malang dan pengusaha kecil di sekitar kampus UIN Maliki Malang. Para karyawan dan pengusaha kecil yang memerlukan biaya pendidikan untuk anak-anaknya dan penambahan modal bagi usahanya, bisa mendapatkan pinjaman dari ElZawa sebesar maksimal Rp 3.000.000,- per-orang.

\section{Pembinaan Usaha Mikro Kecil Menengah (UMKM)}

El-Zawa UIN Maliki melakukan pembinaan kepada anggota UMKM sejumlah 100 orang dengan memberikan pinjaman modal tanpa bunga maksimal Rp 5.000.000,-, informasi, dan kiat seputar pengembangan usaha serta menstiulasi anggota UMKM agar mampu merubah diri dari mustahiq zakat menjadi Muzakki.Saat ini El-Zawa memiliki desa binaan
UMKM di Sumber Pucung, Muharto, dan Lowokwaru.

\section{Mudharabah}

Untuk memproduktifkan dana zakat, El-Zawa telah bekerjasama dengan beberapa pengusaha sukses. Di antaranya adalah program Mudharabah (bagi hasil) dengan peternak jangkrik dan pengrajin alatalat pertanian di desa Sumberpucung. Tidak kurang dari Rp 60.000.000,- dana zakat disalurkan untuk program zakat produktif ini. Hingga 2012 perkembangan usaha yang telah mendapat bantuan permodalan ini berjalan sukses mampu mengurangi remaja pengangguran di daerah tersebut. Bagi pengusaha yang berprestasi, mereka berhak mendapat kucuran dana permodalan pada tahun berikutnya.

\section{Kredit Motor Bebas Uang Muka dan Bunga}

Pada awal 2010, El-Zawa meluncurkan program baru, yakni "kredit motor seharga beli kontan" dengan akad Qordhul Hasan. Secara aplikatif, El-Zawa membuka kesempatan bagi karyawan kontrak terpilih UIN Maliki Malang untuk mendapatkan kendaraan bermotor roda dua tanpa dibebani biaya uang muka dan tanpa bunga. Maksudnya, El-Zawa membelikan motor secara cash dan diserahkan langsung ke peserta program tersebut tanpa tambahan apapun selama 36 bulan. Dengan demikian kredit motor El-Zawa ini dapat menghemat harga motor hingga $60 \%$ jika dibandingkan dengan kredit motor di dealer pada umumnya. Pada periode januari 2012, peserta program kredit motor El-Zawa sebanyak 6 orang, sedangkan pada periode juli 2012 peserta program sebanyak 8 orang. Mereka sangat senang dan berterima kasih dengan adanya program kredit motor tanpa tambahan biaya apapun ini. Program ini rencananya akan terus berlanjut seiring dengan kebutuhan motor pegawai kontrak yang belum terpenuhi.

\section{Pengkajian Zakat dan Waqaf}

Masalah-masalah sengketa waqaf di masyarakat sering kali terjadi. Menyikapi hal itu, El-Zawa UIN Maliki Malang mengdakan pelatihan Nadzir Waqaf di UIN Maliki Malang. Acara tersebut melibatkan para Nadzir Waqaf se-Kota Malang yang meliputi lima kecamatan, yaitu kecamatan Lowokwaru, Klojen, Sukun, Blimbing, dan Kedungkandang.

Pada tahun 2012, El-Zawa berhasil menggelar International Guest Lecture yang menghadirkan Prof. 
Dr. Hasan Bahrom, pakar zakat internasional dari Institut Kajian Zakat (IKaZ) Universiti Teknologi Mara (UiTM) Malaysia, yang dipanelkan dengan Dr. Fakhruddin, M.HI.

\section{Pembahasan}

Standar pengukuran yang digunakan untuk menentukan adanya pengaruh signifikan dalam uji t berpasangan dapat dilihat pada Tabel 3 sebagai berikut:

Tabel 3 Paired Samples Statistics

\begin{tabular}{llcccc}
\hline & & Mean & N & Std. Deviation & Std. Error Mean \\
\cline { 3 - 5 } Pair 1 & Pendapatan Sebelum Pembiayaan & 3783333.33 & 9 & 2201703.886 & 733901.295 \\
& Pendapatan Setelah Pembiayaan & 7388888.89 & 9 & 7044047.921 & 2348015.974 \\
\hline
\end{tabular}

Dari Tabel 3 di atas menunjukkan bahwa ratarata dari harga sebelum kebijakan 3783333.33 dan sesudah kebijakan 7388888.89. Standar deviasi harga sebelum kebijakan 2201703.886 dan sesudah kebijakan 7044047.921.
Tabel 4 (Paire Sample Correlation) di atas menunjukkan adanya hubungan atau korelasi antara sebelum kebijakan dan sesudah kebijakan dengan angka korelasi 0,316 dan signifikansi 0,408.

Tabel 4 Paired Samples Correlations

\begin{tabular}{llccc}
\hline & & N & Correlation & Sig. \\
\hline Pair 1 & Pendapatan Sebelum Pembiayaan \& Pendapatan Setelah Pembiayaan & 9 & .316 & .408 \\
\hline
\end{tabular}

Tabel 5 (Paired Samples Test) ini menunjukkan bahwa rata-rata harga sebelum kebijakan dan sesudah kebijakan menunjukkan angka 3605555.556, standart deviasi 6683582.705 dan standart error 2227860.902.
Tabel 6 (Paired Samples test) menunjukkan berapa nilai terendah dan tertinggi dengan convidence interval $95 \%$ diperoleh hasil nilai terendah -8743012.008 dan nilai tertinggi 1531900.897 .

Tabel 5 Paired Samples Test

\begin{tabular}{llccc}
\hline & & \multicolumn{3}{c}{ Paired Differences } \\
\cline { 3 - 5 } & & Mean & Std. Deviation & Std. Error Mean \\
\hline Pair 1 & $\begin{array}{l}\text { Pendapatan Sebelum Pembiayaan } \\
\text { Pendapatan Setelah Pembiayaan }\end{array}$ & -3605555.556 & 6683582.705 & 2227860.902 \\
\hline
\end{tabular}

Tabel 6 Paired Samples Test

\begin{tabular}{llcr}
\hline & & \multicolumn{2}{c}{$\begin{array}{c}\text { Paired Differences } \\
\text { C5\% Confidence Interval of the Difference }\end{array}$} \\
\cline { 3 - 4 } & & Lower & Upper \\
\hline Pair 1 & $\begin{array}{l}\text { Pendapatan Sebelum Pembiayaan - } \\
\text { Pendapatan Setelah Pembiayaan }\end{array}$ & -8743012.008 & 1531900.897 \\
\hline
\end{tabular}

Tabel 7 Paired Samples Test

\begin{tabular}{llccc}
\hline & & t & Df & Sig. (2-tailed) \\
\hline Pair 1 & $\begin{array}{l}\text { Pendapatan Sebelum Pembiayaan - } \\
\text { Pendapatan Setelah Pembiayaan }\end{array}$ & -1.618 & 8 & .144 \\
\hline
\end{tabular}


Tabel 7 di atas menunjukkan bahwa nilai t hitung menunjukkan angka 1,618 dengan derajad bebas 8 dan signifikansi 0,144.

Berdasarkan Tabel 7 di atas diperoleh hasil bahwa t hitung 1,618 dan t table 2,306, maka Ho ditolak dan $\mathrm{H} 1$ diterima. Jadi diperoleh hasil bahwa terdapat pengaruh Fasilitas Pembiayaan Qardhul Hasan terhadap peningkatan pendapatan UMKM binaan el-Zawa.

\section{KESIMPULAN DAN SARAN}

Dari hasil analisis dan pembahasan mengenai dampak fasilitas pembiayaan dengan menggunakan skim Qardhul Hasan pada produk Qardhul Hasan UMKM di Pusat Kajian Zakat dan Wakaf el-Zawa UIN Maliki Malang dapat ditarik kesimpulan bahwa produk Qardhul Hasan UMKM dapat meningkatkan pendapatan para nasabah. Selain itu, performa pelayanan yang diberikan oleh nasabah dirasa puas oleh para nasabah tersebut.

Adapun saran yang diberikan berkaitan dengan hasil analisis dan pembahasan pada penelitian ini adalah pihak el-Zawa sebaiknya fungsi penilaian dan persetujuan kelayakan nasabah yang selama ini dilakukan oleh pihak eksternal yang diberikan kepercayaan dapat dilakukan petugas internal. Saran bagi peneliti selanjutnya, dianjurkan untuk menganalisis faktor lain yang mempengaruhi peningkatan pendapatan dari para nasabah tersebut.

\section{DAFTAR PUSTAKA}

Ash-Shawi, Shalah dan al-Mushlih, Abdullah. 2008. "Fikih Ekonomi Keuangan Islam”. Jakarta: Darul Haq 2008.
Buku panduan peraturan pemerintah Negara Koperasi dan Usaha Kecil dan Menengah, 2007.

Data Kementrian KUKM tentang Perkembangan UMKM Tahun 2012 dan Data BPS tentang Pertumbuhan PDB Tahun 2012.

Fatwa DSN-MUI Nomor 19/DSN-MUI/IV/2000 tentang prinsip Qardh

http://peuyeumcipatat.blogspot.com/2013/05/ pengertiankriteria-dan-klasifikasi-umkm.html diunduh pada 01/06/2014 pukul 09.15 WIB

http://peuyeumcipatat.blogspot.com/2013/05/ pengertiankriteria-dan-klasifikasi-umkm.html diunduh pada 01/06/2014 pukul 09.15 WIB

http://peuyeumcipatat.blogspot.com/2013/05/ pengertiankriteria-dan-klasifikasi-umkm.html. diunduh pada 01/06/2014 pukul 09.15 WIB

Ridwan, Muhammad. 2004. Manajemen Baitul Mal Wa Tamwil, Yogyakarta: UII Press

Muhammad Syafi' I Antonio.Bank Syariah dari teopi ke praktik. Jakarta: 2001. Gema Insani, 2001. h.160.

Fatwa DSN-MUI Nomor 19/DSN-MUI/IV/2000 tentang prinsip Qardh

Undang Undang Nomor 20 Tahun 2008 tentang UMKM (Usaha Menengah Kecil dan Mikro)

Undang-Undang No.10 Tahun 1998

Wijono, Wiloejo Wirjo. 2005. Pemberdayaan Lembaga Keuangan Mikro Sebagai Salah Satu Pilar Sistem Keuangan Nasional : Upaya Konkrit Memutus Mata Rantai Kemiskinan.Jurnal Kajian Ekonomi dan Keuangan Edisi Khusus 2005. Jakarta

Yayasan penyelenggara penterjemah Al-Quran dan Terjemahannya, Jakarta: Proyek pengadaan kitab suci AlQuran Departemen Agama RI, 1984

Zakiy, Faris Shalahuddin. Dkk. 2014. Triangel Circle Based On Economic Isolation, Sebuah Sistem Pemberdayaan Koperasi Untuk Kesejahteraan Masyarakat Sidogiri. Finalis Cooperative Fair ESCO-FEUI 2014. 